\title{
Predialysis NTproBNP Predicts Magnitude of Extracellular Volume Overload in Haemodialysis Patients
}

\author{
Arkom Nongnuch $^{a, c}$ Kwanpeemai Panorchan ${ }^{b, c}$ Andrew Davenport ${ }^{c}$ \\ ${ }^{a}$ Renal Unit, Department of Medicine, Faculty of Medicine, Ramathibodi Hospital, Mahidol University, Bangkok, \\ ${ }^{b}$ Bumrungrad International Hospital, Bangkok, Thailand; ' UCL Centre for Nephrology, Royal Free Hospital, \\ University College London Medical School, London, UK
}

\section{Key Words}

NT-proBNP · Bioimpedance · Extracellular fluid volume ·

Haemodialysis

\begin{abstract}
Introduction: Increased natriuretic peptides are associated with increased cardiovascular and all-cause mortality for haemodialysis (HD) patients. However, debate continues whether these biomarkers are increased by extracellular water (ECW) excess and can be used to aid clinical assessment of volume status and help determine target weight. Methods: We measured $\mathrm{N}$ terminal probrain natriuretic peptide (NT-proBNP) predialysis in 375 stable haemodialysis outpatients with corresponding pre and postdialysis multifrequency bioelectrical impedance assessments (MFBIA) of (ECW)/total body water (TBW). Results: Median age 64 (5175), $63.9 \%$ male, $42.9 \%$ diabetic, $43.2 \%$ Caucasoid, $14.4 \%$ with a history of myocardial infarction, $8.4 \%$ coronary artery bypass surgery, dialysis vintage 28.2 (12.3-55.5) months. Median predialysis NT-proBNP 283 (123-989) pmol/l, and predialysis ECW/TBW ratio $0.397 \pm 0.029$. On multivariate analysis, predialysis log NT-proBNP was associated with predialysis systolic blood pressure $(\beta 0.007, p=0.000)$, weight $(\beta$ $-0.008, p=0.001)$, valvular heart disease $(\beta 0.342, p=0.015$, $\mathrm{ECW} / \mathrm{TBW}(\beta$ 1.3, $p=0.019)$ and $\log \operatorname{CRP}(\beta 0.145, p=0.037)$.
\end{abstract}

Dividing patients into NTproBNP quartiles, \%ECW/TBW and relative $\mathrm{ECW}$ overhydration were significantly greater for the highest quartile vs. lowest (40.5 \pm 4.1 vs. $39.0 \pm 1.1$, and $1.51 \pm 1.24$ vs. $0.61 \pm 0.69$ l, respectively, $p<0.001)$. Conclusion: In this study, predialysis NTproBNP values were associated with direct assessments of the extracellular volume excess measured by MFBIA and systolic arterial blood pressure. This suggests that predialysis NTproBNP values can potentially be used to aid clinical assessment of volume status in dialysis patients to determine target weight.

(C) 2014 S. Karger AG, Basel

\section{Introduction}

Cardiovascular disease remains the most common cause of death in haemodialysis patients [1]. However, compared to the general population, haemodialysis patients have increased arteriosclerosis and left-ventricular hypertrophy, rather than atheromatous vascular disease. Similarly, haemodialysis patients have an increased prevalence of left-ventricular diastolic dysfunction, which may develop following recurrent episodes of volume overload predialysis [2]. Reducing the number of episodes of volume overload by more frequent dialysis was recently reported to lead to a reduction in both systolic

\begin{tabular}{ll}
\hline KARGER & $\begin{array}{l}\text { ( ) 2014 S. Karger AG, Basel } \\
0250-8095 / 14 / 0403-0251 \$ 39.50 / 0 \quad \text { Karger }\end{array}$ \\
$\begin{array}{l}\text { E-Mail karger@karger.com } \\
\text { www.karger.com/ajn }\end{array}$ & $\begin{array}{l}\text { This is an Open Access article licensed under the terms of the } \\
\text { Creative Commons Attribution-NonCommercial 3.0 Un- } \\
\text { ported license (CC BY-NC) (www.karger.com/OA-license), } \\
\text { applicable to the online version of the article only. Distribu- } \\
\text { tion permitted for non-commercial purposes only. }\end{array}$
\end{tabular}

A. Davenport

UCL Centre for Nephrology, Royal Free Hospital

University College London Medical School

Rowland Hill Street, London NW3 2PF (UK)

E-Mail andrewdavenport@ nhs.uk 
blood pressure and left-ventricular mass [3]. Natriuretic peptides were introduced into routine general medical clinical practice as biomarkers to aid the diagnosis of heart failure. Previous studies have reported a strong inverse association between BNP and survival in dialysis patients [4]. Although BNP is filtered by the glomerulus and degraded in the proximal renal tubules, there is significant extra renal clearance of natriuretic peptides so that many dialysis patients can have normal concentrations [5]. As such there has been debate in the published literature as to whether measurement of natriuretic peptides can add value in aiding clinical judgement of volume status in haemo and peritoneal dialysis patients [6-12]. While NT-proBNP is not affected by peritoneal dialysis exchanges, NT-proBNP concentrations fall after highflux haemodialysis and haemodiafiltration [13]. We therefore elected to determine whether predialysis NTproBNP measurements were increased in patients with an expanded extracellular water space as measured by multifrequency bioelectrical impedance [13].

\section{Methods and Patients}

375 stable established haemodialysis outpatients, attending their routine mid-week haemodialysis session, using either Fresenius $4008 \mathrm{H} / 5000 \mathrm{H}$ or BBraun Dialogue $+{ }^{\circledR}$ dialysis machines with integrated blood pressure monitors (Fresenius Bad Homburg, Germany and BBraun, Melsungen, Germany), polysulfone dialyzers (Nipro Corporation, Osaka, Japan) [14], with ultrapure quality dialysis water and anticoagulation with low molecular weight heparin (Tinzaparin, Leo Laboratories, Princes Risborough, UK) [15] were studied. Multifrequency bio-electrical impedance assessments (MF-BIA) were standardized by taking measurements pre and 20-30 minutes postdialysis session, using an eight-electrode MF-BIA device (Biospace In body 720, Seoul, South Korea) [16, 17]. Patients with pacemakers or implantable defibrillators and amputees were excluded from study. Relative extracellular water volume (ECW) excess termed extracellular water overhydration was estimated according to the method recommended by the European Society for Parenteral and Enteral Nutrition (ESPN) [18].

Serum biochemistry samples were analysed with a standard multi-channel biochemical analyzer (Roche Integra, Roche diagnostics, Lewes, UK), using the bromcresol green method for albumin determination, NT-proBNP was measured by immunoassay (ECLIA Roche Diagnostics, GMBH, Mannhein, Germany), with an inter assay coefficient of variation $1.3 \%$.

Electronic patient medical records were reviewed to obtain relevant clinical information and prescribed medication history.

Ethical approval was granted by the Royal Free Hospital research and development department as audit and clinical service development, and the audit was conducted according to the UK National Health Service guidelines on clinical audit and service development.

\section{Statistical Analysis}

Results are expressed as mean \pm standard deviation, or median and interquartile range, or percentage. Statistical analysis was by Students' paired $t$ test for parametric and the Wilcoxon rank sum pair test for nonparametric data, with Bonferroni correction for multiple analyses where appropriate, and anova with Tukey or Dunnett's post hoc correction (GraphPad Prism version 6.0, GraphPad, San Diego, Calif., USA). Simple correlation analysis was performed with Pearson's rank correlation and then multiple linear regression analysis using backward step multivariate analysis was used excluding variables that were not significant and did not improve the fit of the model, and retaining variables in the model where the $95 \%$ confidence intervals for the estimate did not include zero or there was an improvement in model fit (as demonstrated by the -2log likelihood), using SPSS version 210 (SPSS, Univ Chicago, Ill., USA), which was also used to calculate a receiver operating characteristic curve (ROC) sensitivity and specificity analysis. Nonparametric variables were log transformed to allow analysis. Statistical significance was taken at or below the $5 \%$ level.

\section{Results}

The median age of the 375 patients was 64 (51-75) years, $63.9 \%$ male, $42.9 \%$ diabetic, $43.2 \%$ Caucasoid, $38 \%$ African or Afro-Caribbean, 21.6\% South Asian, with a dialysis vintage of $28.2(12.3-65.5)$ months, and postdialysis body mass index of $26.4 \pm 6.3 \mathrm{~kg} / \mathrm{m}^{2}$. Antihypertensive medications were prescribed to $51.1 \%$ of the patient cohort, with the average number of antihypertensive medications prescribed per patient $1(0-1)$. The commonest antihypertensive medications prescribed were beta blockers $33.2 \%$, followed by calcium channel antagonists at 12.8 and $10.5 \%$ for both angiotensin converting enzyme inhibitors and sartanes. $56.2 \%$ were prescribed aspirin or clopidogrel and $4.8 \%$ warfarin. $14.4 \%$ had a prior documented myocardial infarction, $8.4 \%$ coronary artery bypass surgery, $10.4 \%$ coronary artery stenting, $8.0 \%$ had heart valve replacement or severe valvular heart disease, $10.3 \%$ peripheral vascular disease, and $12.4 \%$ cerebrovascular disease mean dialysis session time 4 (3.5-4.0) hours, urea reduction ratio $74.6 \pm 8.3 \%$. Predialysis haemoglobin $113.4 \pm 13.9 \mathrm{~g} / \mathrm{l}$, serum albumin 40 (37-42) g/l, blood glucose $6.4(5.5-7.8) \mathrm{mmol} / \mathrm{l}$, C-reactive protein 9.4 $(2-11) \mathrm{mg} / \mathrm{l}$. Pre and postdialysis biochemistries, blood pressure and bio-impedance assessments are set out in table 1.

NT-proBNP values were not normally distributed with the median predialysis NT-proBNP 283 (123-989) pmol/l. As such NTproBNP values were log transformed and were correlated with markers of volume overload; extracellular water to total body water ratio (ECW/TBW) 
Table 1. Pre and postdialysis biochemistries, blood pressure and volume assessments

\begin{tabular}{lcc}
\hline & Predialysis & Postdialysis \\
\hline Serum urea, mmol/l & $18.4 \pm 5.3$ & $4.9 \pm 2.5^{* * *}$ \\
Serum sodium, mmol/l & $138.9 \pm 3.3$ & $138.8 \pm 2.9$ \\
Systolic blood pressure, mm Hg & $141.5 \pm 26.0$ & $129.5 \pm 26.0^{* * *}$ \\
Diastolic blood pressure, mm Hg & $75.3 \pm 16.4$ & $71.2 \pm 15.4^{* *}$ \\
Mean arterial blood pressure, mm Hg & $97.0 \pm 17.0$ & $90.2 \pm 17.6^{* * *}$ \\
Intracellular water (ICW), l & $22.7 \pm 5.9$ & $21.5 \pm 4.1^{* * *}$ \\
Extracellular water (ECW), l & $14.9 \pm 3.9$ & $13.4 \pm 2.8^{* * *}$ \\
\% Extracellular water/total body water & $39.7 \pm 2.9$ & $39.0 \pm 1.7^{* * *}$ \\
Weight, kg & $73.6 \pm 19.0$ & $71.8 \pm 19.3^{* * *}$ \\
\hline
\end{tabular}

Variables expressed as mean $\pm \mathrm{SD} .{ }^{* * *} \mathrm{p}<0.001$ vs. predialysis.

Table 2. Multiple regression model for logNTproBNP taken in the predialysis session

\begin{tabular}{lclcccc}
\hline variable & $\beta$ coefficient & SE & $\mathrm{t}$ & $\mathrm{F}$ & 95\% CL & p value \\
\hline SBP, mm Hg & 0.007 & 0.002 & 4.16 & 17.3 & 0.004 to 0.10 & 0.000 \\
Weight, kg & -0.008 & 0.002 & -3.5 & 12.24 & -0.013 to -0.004 & 0.001 \\
Valve & 0.342 & 0.14 & 2.45 & 5.99 & 0.066 to 0.613 & 0.015 \\
\%ECW/TBW & 0.013 & 0.03 & 2.36 & 5.56 & 0.005 to 0.056 & 0.019 \\
log CRP, g/l & 0.145 & 0.069 & 2.10 & 4.4 & 0.009 to 0.281 & 0.037 \\
\hline
\end{tabular}

$\%$ ECW $/ \mathrm{TBW}=$ Percentage extracellular weight/total body water ratio; $\mathrm{SBP}=$ systolic blood pressure; $\mathrm{v}=\mathrm{val}-$ vular heart disease; $\mathrm{CRP}=\mathrm{C}$-reactive protein; $\mathrm{SE}=$ standard error; $\mathrm{CL}=$ confidence limits and adjusted $\mathrm{r}^{2}$ value for model 0.38 .

relative extracellular water overhydration, age, sex, weight cardiovascular disease and also systolic blood pressure (online suppl. table 1; for all online suppl. material, see www.karger.com/doi/10.1159/000368376). We then performed a backward multivariate analysis, excluding variables that were not significant or failed to improve the model fit and log predialysis NTproBNP was associated with ECW/TBW, valvular heart disease, C-reactive protein (CRP), systolic blood pressure, and weight (table 2).

We then divided patients into quartiles of predialysis NTproBNP. Those patients in the highest NTproBNP had greater systolic blood pressure, both pre and postdialysis (fig. 1). Patients in the lowest NTproBNP were heavier, with greater body fat and had higher serum albumin and lower CRP concentrations (table 3). Although bioimpedance assessments did not show absolute differences (table 3), both relative extracellular water overhydration and the ratio of extracellular water (ECW) to total body water (TBW) were greater in those in the highest quartile cohort both pre and postdialysis (fig. 2 and 3 ).

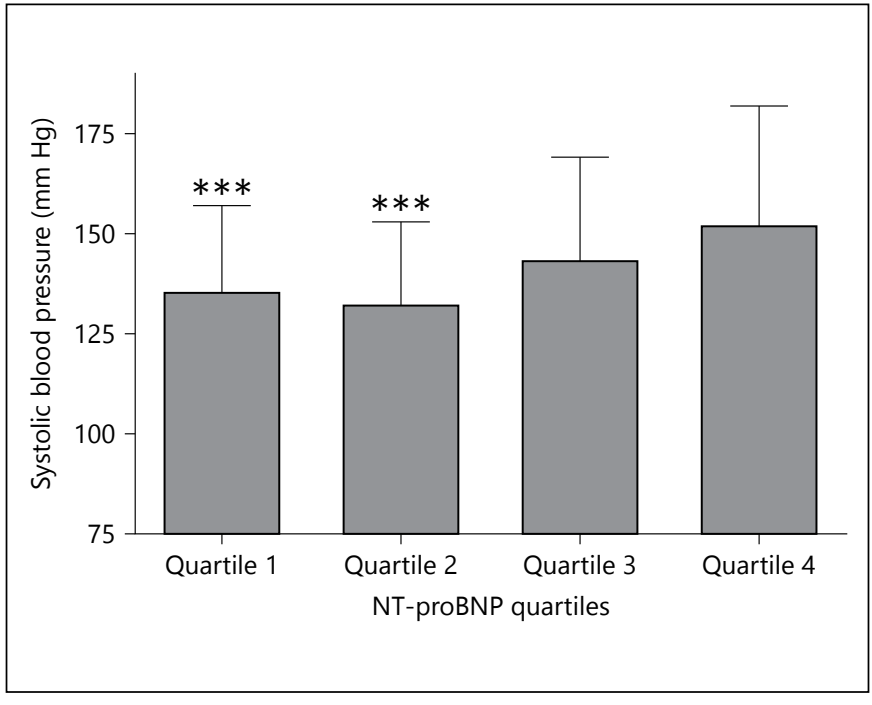

Fig. 1. Systolic blood pressure ( $\mathrm{mm} \mathrm{Hg}$ ) pre dialysis in patients divided into four quartiles according to predialysis NT-proBNP pmol/l. Values expressed as mean \pm SD. ${ }^{* *} \mathrm{p}<0.01$ and ${ }^{* * *} \mathrm{p}<$ 0.001 vs. 4 th quartile (highest NTproBNP group). 
Table 3. Patients divided into predialysis NTproBNP quartiles. Patients prescribed antihypertensive medications (BP meds) and patients prescribed 2 or more different antihypertensive agents ( $\geq 2$ BP meds)

\begin{tabular}{|c|c|c|c|c|}
\hline NTproBNP, pmol/l & $<123$ & $123-283$ & $283-989$ & $>989$ \\
\hline Age, years & $57.1 \pm 16$ & $61.7 \pm 16.7$ & $65.3 \pm 14.1$ & $64.6 \pm 16.2$ \\
\hline Male, \% & 63.8 & 70.0 & 64.1 & 60.9 \\
\hline Diabetic, $\%$ & 42.6 & 35.4 & 47.8 & 46.3 \\
\hline Vintage, months & $22.2(12-58)$ & $27.3(13-63)$ & $28.7(12-67)$ & $43(11-71)$ \\
\hline MI, \% & $5.3^{*}$ & $4.2^{*}$ & 17.4 & 20.4 \\
\hline valve disease, $\%$ & $3.3^{*}$ & $4.2^{*}$ & 8.7 & 17.2 \\
\hline Weight, kg & $79.7 \pm 19.9^{*}$ & $75.6 \pm 20.6^{*}$ & $71.7 \pm 17.5$ & $66.9 \pm 15.4$ \\
\hline ICW, 1 & $24.1 \pm 5.7$ & $23.5 \pm 7.0$ & $21.5 \pm 5.0$ & $21.8 \pm 5.5$ \\
\hline ECW, 1 & $15.4 \pm 3.5$ & $15.2 \pm 4.8$ & $14.3 \pm 3.2$ & $15.9 \pm 4.3$ \\
\hline$\%$ body fat & $31.8 \pm 12.0^{*}$ & $30.1 \pm 11.4$ & $31.3 \pm 11.7$ & $25.0 \pm 13.4$ \\
\hline $\mathrm{CRP}, \mathrm{g} / \mathrm{l}$ & $3(1-8)^{*}$ & $5(2-11)^{*}$ & $5(2-10)$ & $7(3-16)$ \\
\hline URR, \% & $73.7 \pm 8.7$ & $76.0 \pm 6.5$ & $74.8 \pm 8.7$ & $73.4 \pm 8.6$ \\
\hline
\end{tabular}

$\mathrm{MI}=$ Past medical history myocardial infarction; $\mathrm{v}=$ valvular heart disease; $\mathrm{ICW}=$ predialysis weight and bioimpedance volume assessments, intracellular water; ECW = extracellular water; $\mathrm{MAP}=$ mean arterial blood pressure; $\mathrm{CRP}=\mathrm{C}$-reactive protein; $\mathrm{URR}=$ urea reduction ratio. Data expressed as mean \pm standard deviation or median (interquartile range) or percentage. ${ }^{*} \mathrm{p}<0.05$ vs. highest NTproBNP quartile after correcting for multiple testing.

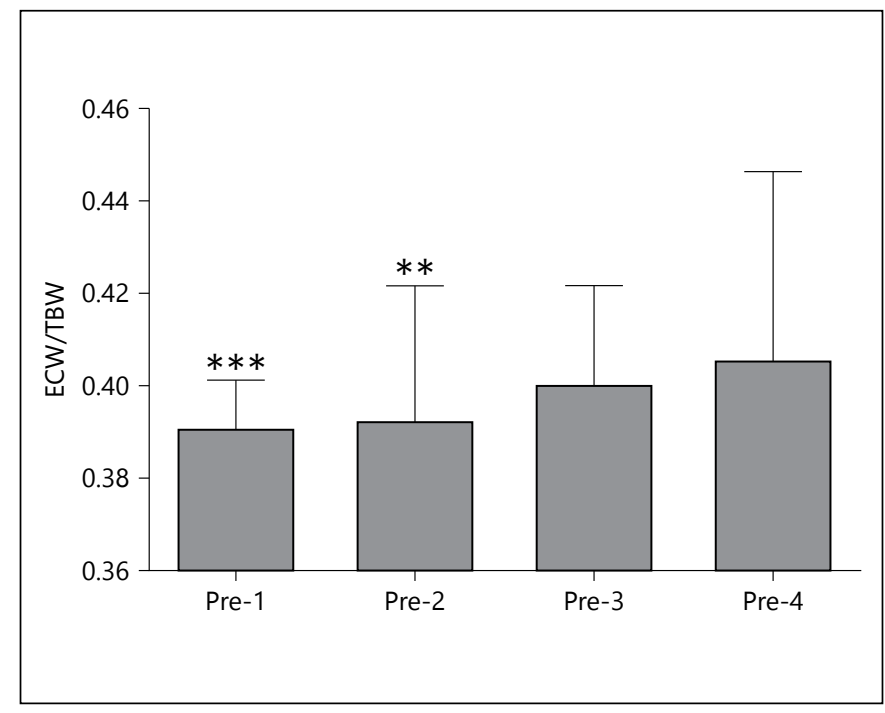

Fig. 2. Extracellular water (ECW) to total body water (TBW) ratio pre dialysis in patients divided into four quartiles according to predialysis NT-proBNP pmol/l. Data expressed as mean \pm SD. ${ }^{* *} \mathrm{p}<0.01$ and ${ }^{* * *} \mathrm{p}<0.001$ vs. 4 th quartile (highest NTproBNP group).

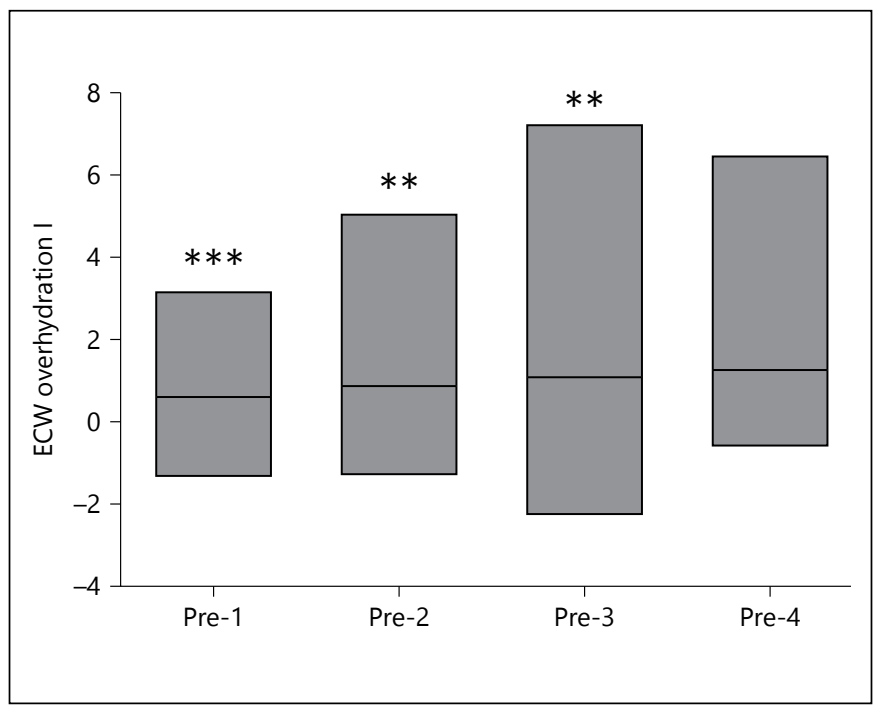

Fig. 3. Relative extracellular water (ECW) overhydration according to ESPEN guidelines pre dialysis, in patients divided into four quartiles according to predialysis NT-proBNP pmol/l. Data expressed as median, interquartile range and minimum to maximum. ${ }^{*} \mathrm{p}<0.05,{ }^{* *} \mathrm{p}<0.01$ and ${ }^{* * *} \mathrm{p}<0.001$ vs. 4 th quartile (highest NTproBNP group). 
Fluid overload in a haemodialysis patient is not simply present or absent, but rather a gradation. We therefore took a pragmatic approach to defining overhydration by using an ECW/TBW ratio of $\geq 0.415$, which was 2 standard deviations from the postdialysis values and $\geq 2.0$ litre ECW excess, as defined by the ESPEN [18]. The relative area under ROC curves for predialysis NTproBNP for an ECW/TBW ratio of $\geq 0.415$ and ECW excess of 2.0 were 0.79 (95\% confidence limits $0.72-0.85)$ and 0.73 (0.65$0.8)$, respectively.

\section{Discussion}

Although previous reports of BNP measurements in dialysis patients have concurred that BNP is a strong prognostic marker for cardiac and all-cause mortality [4], there is debate as to whether BNP has any value in helping to determine volume status in dialysis patients $[10,19]$. In part, this is due to the lack of standardization of the different commercial and locally developed assays for natriuretic peptides, which are now available. Although BNP and NT-proBNP are co-secreted in equimolar amounts from the left and right cardiac ventricles in response to ventricular volume expansion and pressure overload, the larger NTproBNP, has a longer half-life, and is much more stable than BNP [20,21]. BNP values are more variable due to the shorter biological half-life of 10-20 min, but also because BNP is less stable in vitro, especially if blood is not collected into plastic tubes containing EDTA, or without other agents designed to prevent degradation and also if analysis is delayed [22, 23]. Predialysis BNP values vary with the dialysis week, being highest when patients are most volume overloaded prior to the first dialysis session of the week and lowest before the third dialysis session [24]. In addition, while there is little or no clearance with low flux dialysis, some clearance occurs with both high-flux dialysis and haemodiafiltration, although the difference postdialysis is least after the last dialysis session of the week [24]. As such, we chose to standardise the results by making measurements prior to the mid-week dialysis session. In keeping with previous reports, we found that NTproBNP was increased in patients with a history of previous heart disease, including valvular heart disease, myocardial infarction, coronary artery bypass surgery and stenting and the number of antihypertensive drugs prescribed $[4,9]$. The general population-based Framington study, and other studies in haemodialysis patients [11] have reported that overweight patients, and those with a greater body mass

Predialysis NTproBNP and Extracellular

Water in Haemodialysis Patients index had lower NTproBNP concentrations [25]. Our results are in agreement with these findings, but while reports in the general population have linked obesity to lower BNP values [26], we observed greater NTproBNP values in those with lower body fat. This may reflect differences in body composition associated with chronic uraemia and dialysis compared to the healthy general population $[17,27]$.

Although some reports have suggested that BNP does not reflect volume status [10], we found that NTproBNP was greater in those patients with higher systolic blood pressure both pre and postdialysis, and although there was a simple correlation between NTproBNP and systolic blood pressure, the $\mathrm{r}$ value was only 0.303 , and as such, systolic blood pressure accounted only for some $9 \%$ of the variance in NTproBNP in our study population. According to the bioimpedance studies, most of the ECW gain between dialysis sessions is in the legs and trunk. As ECW gain does not directly equate with plasma volume expansion, there is a limited association with systolic blood pressure.

We observed an increased ECW to TBW ratio both pre and postdialysis and NTproBNP, linking NTproBNP to volume overload. In addition, we also expressed ECW excess as relative overhydration as suggested by the ESPEN [18], and again patients with the highest NTproBNP concentrations had greater ECW over-hydration both pre and postdialysis. Although our results support several previous studies $[4,7,8,12]$, the ratio of ECW/TBW can be increased by both expansion of the ECW and reduction in TBW because of a loss of intracellular water [8]. As such, this may link inflammation and malnutrition with volume overload $[8,27-29]$ due to increased vascular permeability. To support this relationship, we observed univariate associations for serum CRP and inverse correlations with serum albumin, haemoglobin and body cell mass. However, on multivariate analysis only CRP remained statistically significant.

We also found that the quartile with the highest NT proBNP concentrations had lower postdialysis weights and although similar dialysis session urea reduction ratios, received shorter dialysis session times. This may suggest that smaller patients receive shorter dialysis session times [30,31], and as such may fail to achieve their target weight as unable to tolerate fluid removal in a shorter period [32]. This would support data that patients of normal body mass index (BMI) and women are reported to have reduced survival on haemodialysis in the United States because they typically have shorter session times compared to men and those with higher BMIs $[29,33]$. 
Our results show that predialysis NTproBNP is increased with extracellular volume overload in haemodialysis patients and as such could potentially be used as a guide to aid clinical judgement in determining the target weight. There is some clearance of NTproBNP with high-flux haemodialysis and haemodiafiltration, but as NTproBNP is one of the larger BNP peptides, clearance is much lower than with other BNP peptides Previous studies have measured postdialysis NTproBNP; however, the area under the ROC curve was somewhat lower 0.72 , and the $95 \%$ confidence limit range was wider at $0.58-0.86$ [11]. As such, predialysis estimations of NTproBNP appear to have greater clinical relevance in helping to assess volume status in dialysis patients. Serial estimations of BNP peptides [19] are more likely to be helpful in monitoring changes in target weight than single-point measurements. Although multi-frequency bioelectrical impedance assessments are an accepted method for assessing volume status in dialysis patients, this technique cannot be used for all patients, particularly those with implantable defibrillators and some car- diac pace makers, and amputees. In addition, total body bioimpedance devices may provide inaccurate estimations of hydration status in haemodialysis patients with unilateral limb swelling or superior vena cava obstruction [33]. As such, there may be a role for measuring natriuretic peptides. Although both pre and post NTproBNP measurements appear to be of similar predictive value, it would be more useful to measure NTproBNP prior to dialysis to aid clinical assessment of volume status, especially as point-of-care testing now allows for bedside monitoring.

\section{Disclosure Statements}

The authors have no conflicts of interest. The data presented has not been previously published in whole or part form.

\section{Source of Funding}

Royal Free Hospital.

\section{References}

1 Foley RN, Parfrey PS: Cardiovascular disease and mortality in ESRD. J Nephrol 1998;11: 239-245.

- Davenport A: How best to improve survival in hemodialysis patients: solute clearance or volume control? Kidney Int 2011;80:1018-1020.

-3 FHN Trial Group, Chertow GM, Levin NW, Beck GJ, Depner TA, Eggers PW, Gassman JJ, Gorodetskaya I, Greene T, James S, Larive B, Lindsay RM, Mehta RL, Miller B, Ornt DB, Rajagopalan S, Rastogi A, Rocco MV, Schiller B, Sergeyeva O, Schulman G, Ting GO, Unruh ML, Star RA, Kliger AS: In-center haemodialysis six times per week versus three times per week. N Engl J Med 2010;363:22872300.

4 Paniagua R, Ventura MD, Avila-Diaz M, Hinojosa-Heredia H, Mendez-Duran A, CuetoManzano A, Cisneros A, Ramos A, Mandonia-Juseino C, Belio-Caro F, Garcia-Contreras F, Trinidad-Ramos P, Vazquez R, Ilabaca B, Alcantara G, Amato D: NT-proBNP, fluid volume overload and dialysis modality are independent predictors of mortality in ESRD patients. Nephrol Dial Transplant 2009;25: 551-557.

5 Papakrivopoulou E, Booth J, Pinney J, Davenport A: Comparison of volume status in asymptomatic haemodialysis and peritoneal dialysis outpatients. Nephron Extra 2012;2:4854.

6 Papakrivopoulou E, Lillywhite S, Davenport $\mathrm{A}$ : Is $\mathrm{N}$-terminal probrain-type natri- uretic peptide a clinically useful biomarker of volume overload in peritoneal dialysis patients? Nephrol Dial Transplant 2012;27: 396-401.

7 Çelik G, Silinou E, Vo-Van C, Jean G, Chazot C: Plasma BNP, a useful marker of fluid overload in hospitalized haemodialysis patients. Hemodial Int 2012;16:47-52.

8 Jacobs LH, van der Kerkhof JJ, Mingels AM, Passos VL, Kleijnen VW, Mazairac AH, van der Sande FM, Wodzig WK, Konings VW, Leunissen KM, van Dieijen-Visser MP, Kooman JP: Inflammation overhydration and cardiac biomarkers in haemodialysis patients: a longitudinal study. Nephrol Dial Transplant 2009;25: 243-248.

-9 Chazot C, Vo-Van C, Zaoui E, Vanel T, Hurot JM, Lorriaux C, Mayor B, Deleaval P, Jean G: Fluid overload correction and cardiac history influence brain natriuretic peptide evolution in incident haemodialysis patients. Nephrol Dial Transplant 2011;26:2630-2634.

10 Agarwal R: B-type natriuretic peptide is not a volume marker among patients on hemodialysis. Nephrol Dial Transplant 2013;28: 3082-3089.

11 Kumar S, Khosravi M, Massart A, Davenport A: Is there a role for $\mathrm{N}$-terminal probrain-type natriuretic peptide in determining volume status in haemodialysis patients? Nephron Clin Pract 2013;122:33-37.

12 Yilmaz Z, Yildirim Y, Aydin FY, Aydin E, Kadiroglu AK, Yilmaz ME, Ulgen MS, Yildiz
A: Relationship between fluid status as assessed by bioimpedance analysis and NT-pro $\mathrm{BNP}$, blood pressure and left ventricular mass index in hemodialysis patients. Clin Ter 2014; 165:e52-e58.

13 Davenport A, Willicombe MK: Comparison of fluid status in patients treated by different modalities of peritoneal dialysis using multifrequency bio-impedance. Int J Artif Organs 2009;32:779-786.

14 Vernon K, Peasegood J, Riddell A, Davenport A: Dialyzers designed to increase internal filtration do not result in significantly increased platelet activation and thrombin generation. Nephron Clin Pract 2011; 117:c403-c408.

15 Davenport A: Low-molecular-weight heparin as an alternative anticoagulant to unfractionated heparin for routine outpatient haemodialysis treatments. Nephrology (Carlton) 2009; 14:455-461.

16 Bedogni G, Malavolti M, Severi S, Poli M, Mussi C, Fantuzzi AL, Battistini N: Accuracy of an eight-point tactile-electrode impedance method in the assessment of total body water. Eur J Clin Nutr 2002;56:11431148.

17 Fürstenberg A, Davenport A: Comparison of multifrequency bioelectrical impedance analysis and dual-energy X-ray absorptiometry assessments in outpatient haemodialysis patients. Am J Kidney Dis 2011;57:123129. 
18 Kyle UG, Bosaeus I, De Lorenzo AD, Deurenberg P, Elia M, Gómez JM, Heitmann BL, Kent-Smith L, Melchior JC, Pirlich M, Scharfetter H, Schols AM, Pichard C; Composition of the ESPEN Working Group: Bioelectrical impedance analysis - part I: review of principles and methods. Clin Nutr 2004;23:12261243.

19 Davenport A: Changes in N-terminal probrain natriuretic peptide correlate with fluid volume changes assessed by bioimpedance in peritoneal dialysis patients. Am J Nephrol 2012;36:371-376.

20 Gruson D, Ketelslegers JM, Verschuren F, Thys F: Head-to-head comparison of the prohormone proBNP1-108 with BNP and NtproBNP in patients admitted to emergency department. Clin Biochem 2012;45:249-252.

-21 Emdin M, Passino C, Prontera C, Fontana M, Poletti R, Gabutti A, Mammini C, Giannoni A, Zyw L, Zucchelli G, Clerico A: Comparison of brain natriuretic peptide (BNP) and amino-terminal ProBNP for early diagnosis of heart failure. Clin Chem 2007;53:1289-1297.

22 Lippi G, Fortunato A, Salvagno GL, Montagnana $M$, Soffiati G, Guidi GC: Influence of sample matrix and storage on BNP measurement on the Bayer Advia Centaur. J Clin Lab Anal 2007;21:293-297.
23 Miller WL, Phelps MA, Wood CM, Schellenberger U, Van Le A, Perichon R, Jaffe AS: Comparison of mass spectrometry and clinical assay measurements of circulating fragments of B-type natriuretic peptide in patients with chronic heart failure. Circ Heart Fail 2011;4:355-360.

24 Sheen V, Bhalla V, Tulua-Tata A, Bhalla MA, Weiss D, Chiu A, Abdeen O, Mullaney S, Maisel A: The use of B-type natriuretic peptide to assess volume status in patients with end-stage renal disease. Am Heart J 2007; 153 : 244.e1-e5.

5 Das SR, Drazner MH, Dries DL, Vega GL, Stanek HG, Abdullah SM, Canham RM, Chung AK, Leonard D, Wians FH Jr, de Lemos JA: Impact of body mass and body composition on circulating levels of natriuretic peptides: results from the Dallas Heart Study. Circulation 2005;112:2163-2168.

26 Wang TJ, Larson MG, Levy D, Benjamin EJ, Leip EP, Wilson PW, Vasan RS: Impact of obesity on plasma natriuretic peptide levels. Circulation 2004; 109:594-600.

27 Fürstenberg A, Davenport A: Assessment of body composition in peritoneal dialysis patients using bioelectrical impedance and dualenergy x-ray absorptiometry. Am J Nephrol 2011;33:150-156
28 Booth J, Pinney J, Davenport A: N-terminal proBNP - marker of cardiac dysfunction, fluid overload, or malnutrition in hemodialysis patients? Clin J Am Soc Nephrol 2010;5: 1036-1040.

29 Chazot C, Jean G, Vo-Van C, Collonge C, Terrat JC, Vanel T, Lorriaux C, Hurot JM, Charra $\mathrm{B}$ : The plasma level of brain natriuretic peptide is increased in malnourished haemodialysis patients. Blood Purif 2009;28:187-192.

30 Davenport A: Differences in prescribed Kt/V and delivered haemodialysis dose - why obesity makes a difference to survival for haemodialysis patients when using a 'one size fits all' Kt/V target. Nephrol Dial Transplant 2013; 28(suppl 4):iv219-iv223.

31 Spalding EM, Chandna SM, Davenport A, Farrington $\mathrm{K}: \mathrm{Kt} / \mathrm{V}$ underestimates the haemodialysis dose in women and small men. Kidney Int 2008;74:348-355.

32 Booth J, Pinney J, Davenport A: Do changes in relative blood volume monitoring correlate to hemodialysis-associated hypotension? Nephron Clin Pract 2011;117:c179-c183.

33 Kumar S, Khosravi M, Massart A, Potluri M, Davenport A: Changes in upper limb extracellular water content during haemodialysis measured by multi-frequency bioimpedance. Int J Artif Organs 2013;36:203-207. 